\title{
Role of Arginine Vasopressin in Blood Pressure Control in Young Rats
}

\author{
PETER HERIN, ${ }^{(19)}$ ANN-CHRISTINE EKLÖF, AND ANITA APERIA \\ Department of Pediatrics, St Göran's Hospital and the Department of Pediatrics, Huddinge Hospital, \\ Stockholm, Sweden.
}

\begin{abstract}
Summary
We investigated the importance of arginine-vasopressin (AVP) for blood pressure control in young and adult rats. Most of the studies were performed on Brattleboro rats with complete diabetes insipidus (DI). In some protocols, Sprague-Dawley rats (SD) were also used. The rats were age 20-24 days (young) or 50-80 days (adult). Adult DI rats have a significantly higher mean arterial pressure (MAP) than adult SD rats. The studies were performed during normovolemia and hypovolemia. Hypovolemia was created by the rapid withdrawal of blood, $0.5-1.5 \%$ of body weight. Following bleeding $0.5 \%$ of the body weight, young DI rats had a significantly larger decrease in MAP than adult DI and young and adult SD rats. Continuous infusion of AVP (2000 $\left.\mathrm{pg} \cdot 100 \mathrm{~g}^{-1} \mathrm{~min}^{-1}\right)$ blunted the hemorrhagic hypotension in the DI rats.

In all groups of rats studied, AVP had little effect on the MAP during normovolemia. The effect of AVP (given in a bolus dose of 20 or $2000 \mathrm{pg} \cdot 100 \mathrm{~g}^{-1}$ ) on the MAP was in DI rats significantly related to the MAP immediately prior to the AVP administration. No effect on MAP was observed when the initial MAP was 105$112 \mathrm{~mm}$ in the young DI rats and $148-157 \mathrm{~mm}$ in the adult DI rats. The effect of AVP $\left(20 \mathrm{pg} \cdot 100 \mathrm{~g}^{-1}\right)$ appeared to be submaximal to maximal. In anaesthetized SD rats, the basal AVP production was higher in the young than in the adult animals. Following bleeding, serum AVP increased in both young and adult rats but the increase was significant only in the adult rats.
\end{abstract}

\section{Abbreviations}

AVP, arginine vasopressin

DI, diabetes insipidus

BW, body weight

SD, Sprague-Dawley

MAP, mean arterial pressure

Several investigators have reported that the serum levels of AVP are high in the perinatal period $(9,10)$. Pohjavuori and Fyhrquist (9) found that the AVP levels in serum from cord blood could be 100 times higher than in serum from the mother.

It is generally recognized that AVP may have both an antidiuretic (14) and a hemodynamic effect $(3,6,10)$. It is also well documented that the response to the antidiuretic effect is not fully developed at birth $(12,13)$. Newborn infants given high doses of DDAVP intranasally continue to produce an almost isotonic urine (15). Studies on isolated collecting tubules from rabbits have shown that the maximal increase in cAMP following exposure to AVP is significantly less in immature than in mature collecting tubules (13). Pohjavuori and Fyhrquist (9) therefore suggested that the high AVP production in the perinatal period was of importance primarily for blood pressure control.
The vascular effects of AVP are less well investigated than the antidiuretic effects. The doses of AVP generally required to elicit significant changes in blood pressure are often 100 to 1000 times higher than the doses required to produce antidiuretic effects. The fact that hemorrhage is a potent stimulus for AVP release $(4,5)$ suggests that AVP is important for the prevention of hemorrhagic hypotension.

The aim of this study was to evaluate the role of AVP for blood pressure control in hemorrhagic hypotension in young rats. Most of the experiments were performed on Brattleboro rats with hereditary DI. Only homozygote animals with a complete lack of AVP were used. By using this strain, we unmasked the hemodynamic effect of endogenous AVP.

\section{MATERIALS AND METHODS}

The experiments were carried out on Brattleboro (16) and Sprague-Dawley rats age 20-24 days (young rats) and 50-80 days (adult rats). The Brattleboro rats in this study had a hypotonic urine osmolality following $19 \mathrm{~h}$ of dehydration. They had a high incidence of hydronephrosis, which may be interpreted as a sign of polyuria. They were therefore judged to be homozygotic with regard to the inherited defect of AVP production and will be referred to as DI rats. The animals were given an ordinary laboratory diet and had free access to fluids.

The rats were anaesthetized with Inactin (Byk) $8 \mathrm{mg} \cdot 100 \mathrm{~g}^{-1}$ BW and an endotracheal tube was inserted. A thin polyethylene catheter was introduced into a carotid artery for blood pressure recordings and withdrawal of blood and another catheter was introduced into a femoral vein for infusions and blood sampling. We used only rats that did not bleed during the preparation for further studies. During the experiments a saline solution was administered at a rate of $3 \mathrm{ml} \cdot 100 \mathrm{~g}^{-1} \mathrm{BW} \mathrm{h}^{-1}$ to the DI rats and at a rate of $1 \mathrm{ml} \cdot 100 \mathrm{~g}^{-1} \mathrm{BW} \mathrm{h} \mathrm{h}^{-1}$ to the SD rats. The differences in infusion rates were based on differences in urine production. The hematocrit values did not change during the course of the study. They averaged $30 \pm 4.5$ and $36 \pm 2.6$ in young and adult DI rats, respectively. We have previously found in rats that the hematocrit values increase between 20 and 40 days of age (1). The MAP was recorded continuously with a Grass polygraph by means of a Statham transducer. The hematocrit of heparinized blood samples was determined in glass capillaries after centrifuging at $5000 \mathrm{rpm}$ for $5 \mathrm{~min}$.

Bleeding. After a control period of $10 \mathrm{~min}$, blood $(0.5-1.5 \mathrm{ml}$. $100 \mathrm{~g}^{-1} \mathrm{BW}$ ) was rapidly withdrawn from the carotid artery catheter. The MAP was followed continously for up to $10 \mathrm{~min}$ after the reduction in blood volume. The animals were then retransfused.

AVP administration. AVP (supplied by the Ferring Co. Malmö, Sweden) was dissolved in $0.9 \% \mathrm{NaCl}$ and $0.1 \%$ bovine serum albumin ( $1 \mathrm{U}$ AVP $=2.5 \mathrm{pg}$ ). In some experiments, AVP 
was infused continuously and intravenously at the rate of 2000 $\mathrm{pg} \cdot 100 \mathrm{~g}^{-1} \mathrm{BW} \mathrm{min}^{-1}$. The infusion was started $10 \mathrm{~min}$ before and continued $10 \mathrm{~min}$ after the bleeding. In other experiments, AVP was injected as a bolus dose intravenously $\left(20 \mathrm{pg} \cdot 100 \mathrm{~g}^{-1}\right.$ BW or $\left.2000 \mathrm{pg} \cdot 100 \mathrm{~g}^{-1} \mathrm{BW}\right)$. The AVP was then injected either during control conditions or 2 min after withdrawal of $0.5-1.5$ ml blood. $100 \mathrm{~g}^{-1} \mathrm{BW}$. In animals given a bolus dose of AVP, MAP was registered $30 \mathrm{sec}$ before the injection and $30 \mathrm{sec}$ after the injection was completed.

$A V P$ and angiotensin determinations. Blood $(0.3 \mathrm{ml})$ for the determination of AVP levels was taken from the SD rats during control conditions and $3 \mathrm{~min}$ following withdrawal of $1 \mathrm{ml}$ blood $\cdot 100 \mathrm{~g}^{-1} \mathrm{BW}$. The AVP concentration in serum was determined with radioimmunoassay. One-half $\mathrm{ml}$ blood was taken from adult DI and SD rats during control conditions and $3 \mathrm{~min}$ followig withdrawal of $1 \mathrm{ml}$ blood $\cdot 100 \mathrm{~g}^{-1} \mathrm{BW}$. The angiotensin II concentration in serum was determined with radioimmunoassay.

Calculation. Student's $t$ test, paired $t$ test, and multivariate linear regression analysis were used in the statistical analyses. Values are given as the mean $\pm \mathrm{SD} ; P$ values less than 0.05 are considered significant.

\section{RESULTS}

The MAP recorded under control conditions did not differ significantly in young DI and SD rats (Table 1). As reported previously (1), the MAP increased significantly from about 20 days of age to adulthood. The increase was significantly more pronounced in the DI rats than in the SD rats.

MAP during bleeding. The effect of a moderate bleeding $(0.5 \%$ of BW) on the MAP is demonstrated in Figure 1. The MAP is presented in percentage of the MAP value recorded immediately before the bleeding. In all of the groups studied, the bleeding induced a fall in the MAP. This fall was significantly more pronounced in the young DI rats than in the young SD rats, the adult DI rats, and the adult SD rats. In the young DI rats, the average maximal decrease in the MAP, occurring within $30 \mathrm{sec}$ following the bleeding, was $60 \%$ of the control value. There was no significant difference in the MAP response between the adult $\mathrm{DI}$ and the adult SD rats during hemorrhage.

MAP following AVP administration. Infusion of AVP (2000

Table 1. Mean arterial blood pressure during control conditions

\begin{tabular}{lcc}
\hline & $n$ & MAP $(\mathrm{mm} \mathrm{Hg})$ \\
\hline Young DI rats & 58 & $109 \pm 19^{*}$ \\
Adult DI rats & 18 & $164 \pm 20 \dagger$ \\
Young SD rats & 16 & $101 \pm 12^{*}$ \\
Adult SD rats & 15 & $143 \pm 12$ \\
\hline
\end{tabular}

* Significantly different from adult DI rats.

† Significantly different from adult SD rats.

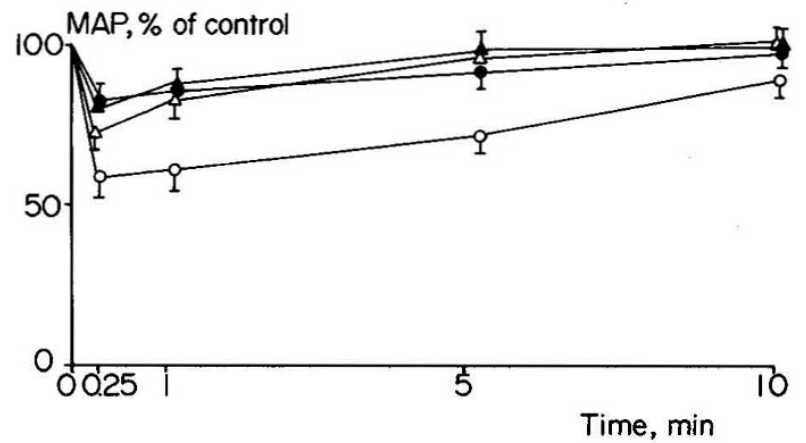

Fig. 1. Mean arterial blood pressure (in percentage of control value) during bleeding $(0.5 \%$ of $\mathrm{BW})$ in young $(\mathrm{O}, n=20)$ and adult $(\Theta, n=$ 11) Brattleboro rats and in young $(\Delta, n=11)$ and adult $(\Delta, n=11)$ Sprague-Dawley rats. $\mathrm{pg} \cdot 100 \mathrm{~g}^{-1} \mathrm{BW} \mathrm{min}^{-1}$ ) increased the MAP somewhat more in the young than in the adult DI rats (11.4 and 5\%, respectively). When the rats were bled during a continuous infusion of AVP $\left(2000 \mathrm{pg} \cdot 100 \mathrm{~g}^{-1} \mathrm{BW} \cdot \mathrm{min}^{-1}\right)$, the fall in MAP was blunted in the young DI rats when bled $0.5 \%$ of the BW (Fig. 2). The same degree of inhibition in pressure fall was observed in the adult DI rats when bled $1 \%$ of the BW. The effect of AVP on MAP thus appeared to be more pronounced during hemorrhagic hypotension than during control conditions. The relationship between the initial MAP and the effect of AVP on the MAP was therefore tested by giving bolus doses of AVP $\left(20\right.$ and $\left.2000 \mathrm{pg} \cdot 100 \mathrm{~g}^{-1}\right)$ to young and adult rats during control conditions, as well as after bleeding. The rats were bled $0.5,1$, or $1.5 \%$ of the BW to obtain a wide range of initial MAP values. We found a close inverse relationship between the initial MAP and the MAP-elevating effect of AVP in both age groups (Fig. 3, $A$ and $B$ ). The $r$ values for 20 and $2000 \mathrm{pg} \cdot 100 \mathrm{~g}^{-1}$ in infants DI rats were -0.90 and -0.93 , respectively, and in adult DI rats -0.93 and -0.88 , respectively (Fig. $3 C$ ). When the MAP was high (during control conditions), AVP caused only small MAP increases and in some cases (hypertensive adult DI rats) it even reduced the MAP. No change in MAP was observed when the initial MAP was 105$112 \mathrm{~mm} \mathrm{Hg}$ in the young DI rats and $148-157 \mathrm{~mm} \mathrm{Hg}$ in the adult DI rats (Fig. $3 C$ ). The lower values for no effect were observed following the higher dose of AVP. The difference between the effect of 20 and $2000 \mathrm{pg}$ AVP, however, was not significant in either the young or the adult rats. No effect of AVP on MAP occurred at a significantly lower MAP in the young than in the adult rats for both AVP 20 and $2000 \mathrm{pg} \cdot 100 \mathrm{~g}^{-1}$. The intercepts of the regression line between the initial MAP and an increase in the MAP following AVP differed significantly in the young and the adult DI rats.

$A V P$ and angiotensin levels. Serum samples for the determination of the AVP concentration were taken before and following bleeding ( $1 \%$ of BW) in SD rats. The AVP level during control conditions was significantly lower in the adult than in the young rats (Table 2). The mean AVP concentration increased in both age groups following bleeding but the increase was significant only in the adults rats. Serum samples for the determination of angiotensin were obtained in adult DI and SD rats (Table 3). The angiotensin levels did not differ significantly during control conditions; they increased to a similar degree after bleeding ( $1 \%$ of BW) in both groups.

\section{DISCUSSION}

Several previous studies have suggested that AVP has a dual effect on blood pressure control $(4,8)$, a peripheral blood pressure-elevating effect and a central blood pressure-depressing effect. It is well documented that AVP has a contracting effect on endothelial smooth muscle cells (2). In baroreceptor denervated animals, the MAP is depressed (8), but the MAP-elevating effect

Infant DI-rats

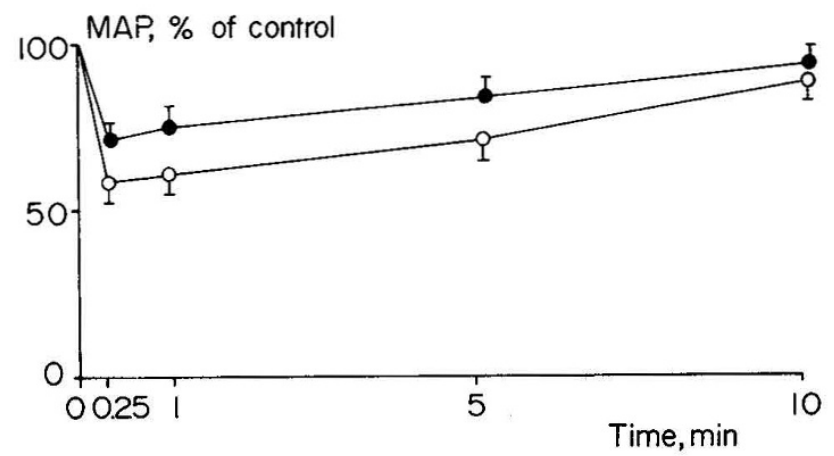

Fig. 2. Mean arterial blood pressure (in percentage of control value) during bleeding $(0.5 \%$ of $\mathrm{BW})$ in young Brattleboro rats without $(\mathrm{O}, n=$ $11)$ and during a continuous AVP infusion $(\bullet, n=15)$. 
Infant DI-rats

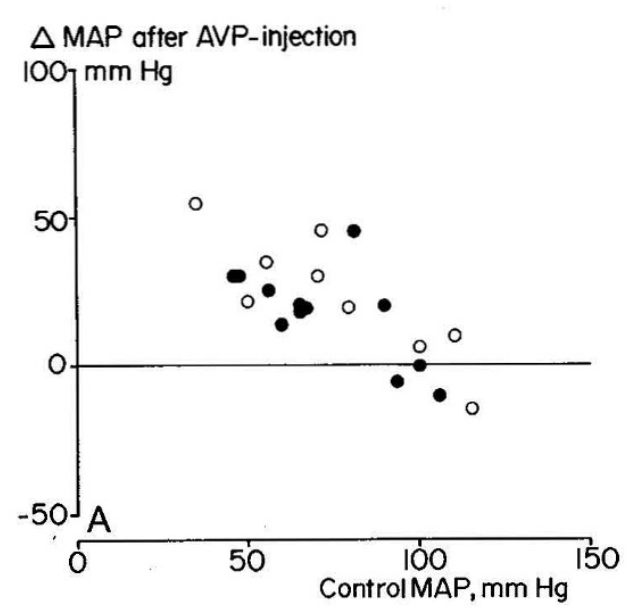

Adult DI-rats

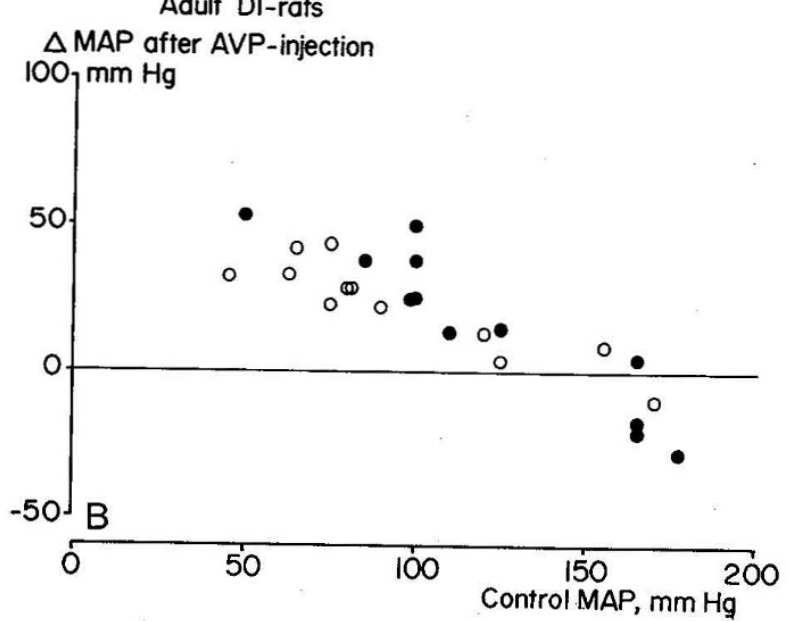

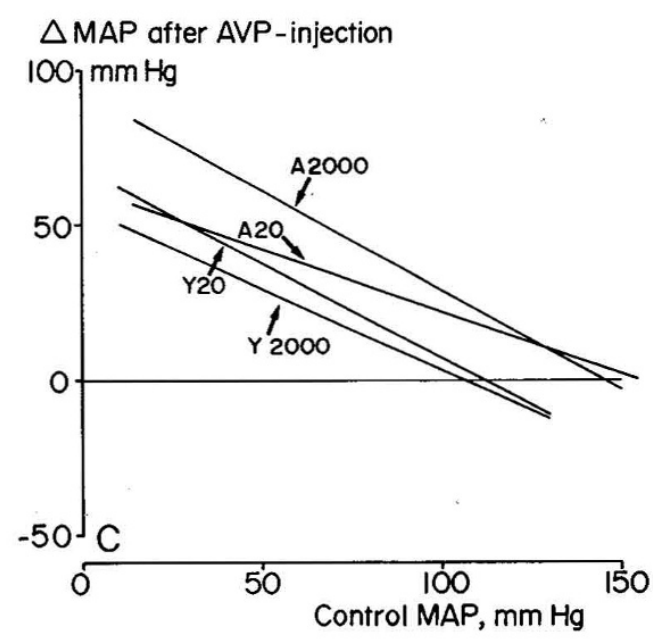

Fig. 3. Relationship in young and adult Brattleboro rats between initial MAP and change in MAP following a bolus dose of AVP, $20 \mathrm{pg} \cdot 100 \mathrm{~g}$ $(O)$ and $2000 \mathrm{pg} \cdot 100 \mathrm{~g}^{-1}(\bullet)$. Individual values $(A$ and $B)$ as well as regression lines $(C)$ are presented. $Y$, young rats; $A$, adult rats. 20 , AVP dose of $20 \mathrm{pg} \cdot 100 \mathrm{~g}^{-1} ; 2000$, AVP dose of $\left.2000 \mathrm{pg} \cdot 100 \mathrm{~g}^{-1}\right)$.

Table 2. Serum levels of $A V P$ in young and adult $S D$ rats during control conditions and following bleeding*

\begin{tabular}{ccc}
\hline & \multicolumn{2}{c}{$\mathrm{AVP}\left(\mathrm{pg} \cdot \mathrm{ml}^{-1}\right)$} \\
\cline { 2 - 3 } & \multicolumn{1}{c}{ Control } & Bleeding \\
\hline Young SD rats $(n=7)$ & $45.0 \pm 11.0$ & $49.1 \pm 13.4$ \\
Adult SD rats $(n=7)$ & $21.0 \pm 2.8$ & $41.6 \pm 16.5 \dagger$ \\
\hline
\end{tabular}

* Values are mean $\pm \mathrm{SD}$.

$\dagger$ Significantly different from control adult SD rats but not significantly different from bled young SD rats.

Table 3. Serum levels of angiotensin I in adult DI and SD rats during control conditions and following bleeding*

\begin{tabular}{ccc}
\hline & \multicolumn{2}{c}{$\begin{array}{c}\text { Angiotensin } \mathrm{I} \\
\left(\mathrm{ng} \cdot \mathrm{ml}^{-1} \mathrm{~h}^{-1}\right)\end{array}$} \\
\cline { 2 - 3 } & Control & Bleeding \\
\hline Adult DI rats $(n=4)$ & $10.4 \pm 4.7$ & $45.3 \pm 16.2 \dagger$ \\
Adult SD rats $(n=4)$ & $13.4 \pm 6.0$ & $42.0 \pm 10.9 \ddagger$ \\
\hline
\end{tabular}

* Values are mean \pm SD.

$\dagger$ Significantly different from control adult DI rats but not significantly different from bled adult SD rats.

$\ddagger$ Significantly different from control adult SD rats. of AVP is greatly enhanced. These observations support the hypothesis that AVP mediates a central blood pressure-depressing effect. This dual effect on blood pressure means that AVP plays an important role in normal blood pressure control. In adult DI rats, AVP increased the blood pressure during hypotension and reduced it during hypertension. AVP had no effect on the blood pressure (MAP) when it was around $150 \mathrm{~mm} \mathrm{Hg}$, which is approximately the same MAP as that recorded in control adult SD rats. In young rats, AVP had no measurable effect on the MAP when it was around $110 \mathrm{~mm} \mathrm{Hg}$. It is therefore possible that changes in the balance between the vasoconstrictive effect of AVP and the central depressing effect of AVP occur during postnatal life. The change in balance between the different hemodynamic effects of AVP may be of importance in the control of the MAP during development and in the adult. It is of interest in this connection that the MAP in adult DI rats is significantly higher than in adult SD rats.

AVP appears to play a physiological role in the prevention of hemorrhagic hypotension. In previously reported studies on the hemodynamic importance of AVP, its blood pressure-elevating effects have been most apparent following hemorrhage and followig baroreceptor denervation $(4,7,8,12,17)$. The results of the present study imply that AVP is of even greater importance in the prevention of hemorrhagic hypotension in young than in adult rats. We found that a moderate blood volume contraction, $0.5 \%$ of the $\mathrm{BW}$, caused a more pronounced hypotension in 
young DI rats than in young SD rats and adult DI and SD rats. We also found that this hypotension could be prevented by the continuous infusion of AVP $\left(2000 \mathrm{pg} \cdot 100 \mathrm{~g}^{-1} \mathrm{~min}^{-1}\right)$. The adult DI rats were more resistant to hemorrhagic hypotension than the infant DI rats. The reason for this is not known. In addition to AVP, angiotensin has also been thought to prevent hemorrhagic hypotension. The angiotensin levels were the same in the adult DI and SD rats both during control conditions and following bleeding. It is therefore likely that the relative resistance to hemorrhagic hypotension, observed in adult DI rats, is independent of angiotensin.

The serum AVP levels were measured in the SD rats. The capacity to release AVP was at least as good in young as in adult rats. Previous studies on fetal lambs have shown that the capacity to release AVP in response to blood volume contraction is well developed even in fetal life (12). The AVP levels recorded under basal conditions were high in both the adult and the infant DI rats; they were 21 and $45 \mathrm{pg} \cdot \mathrm{ml}^{-1}$, respectively. In adult rats that have been dehydrated for $48 \mathrm{~h}$, the AVP concentration has been reported to be around $30 \mathrm{pg} \cdot \mathrm{ml}^{-1}(5)$. The SD rats in this study had been dehydrated for $10 \mathrm{~h}$ and subjected to anesthesia and blood vessel cannulation which might have caused the blood volume contraction. Great care had, however, been taken not to use animals that had been bled prior to carrying out the procedure. Following bleeding, the AVP levels increased in both groups, but the increase was significant only in the adult rats. It is possible, however, that the AVP levels in the infant rats were already so high during basal conditions that they represented maximal levels.

\section{REFERENCES AND NOTES}

1. Aperia A, Herin P 1975 Development of glomerular perfusion rate and nephron filtration rate in rats 17-60 days old. Am J Physiol 228:1319

2. Ausiello D, Kreisberg J, Roy C, Karnosky M 1980 Contraction of cultured rat glomerular cells of apparent mesangial origin after stimulation with angiotensin II and arginine vasopressin. J Clin Invest 65:754
3. Claybaugh JR, Share L 1973 Vasopressin, renin and cardiovascular responses to continuous slow hemorrhage. Am J Physiol 224:519

4. Cowley AW Jr, Switzer SJ, Guinn MM 1980 Evidence and quantification of the vasopressin arterial pressure control system in the dog. Circ Res 46:58

5. Fyhrquist F, Tikkanen I, Linkola J 1981 Plasma vasopressin concentration and renin in the rat: Effect of hydration and hemorrhage. Acta Physiol Scand 113:507

6. Hall CE, Ayachi S, Hall SA 1973 Spontaneous hypertension in rats with hereditary hypothalamic diabetes insipidus. Tex Rep Biol Med 31:471

7. Laycock JF, Penn W, Shirley DG, Walter SJ 1979 The role of vasopressin in blood pressure regulation immediately following acute hemorrhage in the rat. J Physiol 296:267

8. Montani J-P, Liard J-F, Schoun J, Möhring J 1980 Hemodynamic effects of exogenous and endogenous vasopressin at low plasma concentrations in conscious dogs. Circ Res 47:346

9. Pohjavuori M, Fyhrquist F 1980 Hemodynamic significance of vasopressin in the newborn infant. J Pediatr 97:462

10. Pullan PT, Johnston CI, Anderson WP, Korner PI 1980 Plasma vasopressin in blood pressure homeostasis and in experimental renal hypertension. Am J Physiol 239:H81

11. Rees L, Forsling ML, Brook CG 1980 Vasopressin concentrations in the neonatal period. Clin Endocrinol 12:357

12. Robillard JE, Weitzman RE, Fisher DA, Smith FG Jr, 1979 The dynamics of vasopressin release and blood volume regulation during fetal hemorrhage in the lamb fetus. Pediatr Res 13:606

13. Schlondorff D, Weber H, Trizna H, Fine LG 1978 Vasopressin responsiveness of renal adenylate cyclase in newborn rats and rabbits. Am J Physiol 234:F16

14. Schrier RW, Berl T, Anderson RJ 1979 Osmotic and nonosmotic control of vasopressin release. Am J Physiol 236:F321

15. Svenningsen NW, Aronson AS 1974 Postnatal development of renal concentration capacity, as estimated by DDAVP test in normal and asphyxiated neonates. Biol Neonate 25:230

16. Valtin H 1976 Animal model of human disease: hereditary hypothalamic diabetes insipidus. Am J Pathol 83:633

17. Weitzman RE, Reviczky A, Oddie TH, Fisher DA 1980 Effect of osmolality on arginine vasopressin and renin release after hemorrhage. Am J Physiol 238:E62

18. This research was supported by grants from the Swedish Medical Research Council (06263) and from the Expressen Newspaper Prenatal Fund. The preliminary results of this study were presented at the Symposium on the Brattleboro Rat in the U. S. A., September 1981.

19. Requests for reprints should be addressed to: Peter Herin, Department of Pediatrics, St Göran's Hospital, Box 12500, S-112 81 Stockholm, Sweden. 20. Received for publication October $25,1983$.

\title{
Abnormal Fatty Acid Turnover in the Phospholipids of the Red Blood Cell Membranes of Cystic Fibrosis Patients (in Vitro Study)
}

\author{
VERA ROGIERS ${ }^{(28)}$, ISIDOOR DAB, YVETTE MICHOTTE, ANTOINE VERCRUYSSE, \\ ROBERT CROKAERT, AND HENRI L. VIS \\ Department of Pharmacognosy, Phytochemistry and Toxicology [V. R., A. V.], Department of Pediatrics [I. D., \\ H. L. V.], Department of Pharmaceutical and Biomedical Analyses [Y. M.], and Department of Biochemistry \\ [R. C.J, Free University of Brussels, Laarbeeklaan, 103, B-109 Brussels, Belgium
}

\begin{abstract}
Summary
A study was carried out in order to investigate whether the abnormal in vitro turnover of fatty acids in the phospholipids of the red blood cell membranes of cystic fibrosis patients is intrinsic to the membrane, or whether it is induced by extrinsic serum factors. Red blood cells of cystic fibrosis patients and healthy subjects were labeled in vitro with $\left[{ }^{14} \mathrm{C}\right]$ linoleic acid, bound to
\end{abstract}

albumin. The labeled cells were reincubated in autologous and homologous serum. The radioactivity present in the serum lipids and in the major phospholipid fractions of the red cell membranes was measured.

Conclusions of this study are: 1) not all of the cystic fibrosis patients examined individually show an abnormal in vitro turnover of the red cell fatty acids, although they all presented abnormal fatty acid patterns for the red blood cell phospholipids, 